\title{
Management of diabetes mellitus in patients with chronic kidney disease
}

\author{
Allison J. Hahr and Mark E. Molitch*
}

\begin{abstract}
Glycemic control is essential to delay or prevent the onset of diabetic kidney disease. There are a number of glucose-lowering medications available but only a fraction of them can be used safely in chronic kidney disease and many of them need an adjustment in dosing. The ideal target hemoglobin A1c is approximately $7 \%$ but this target is adjusted based on the needs of the patient. Diabetes control should be optimized for each individual patient, with measures to reduce diabetes-related complications and minimize adverse events. Overall care of diabetes necessitates attention to multiple aspects, including reducing the risk of cardiovascular disease, and often, multidisciplinary care is needed.
\end{abstract}

Keywords: Diabetes, Chronic kidney disease, Diabetic kidney disease, Nephropathy, Glycemic control, Hemoglobin A1c

\section{Introduction}

Diabetes mellitus is a growing epidemic and is the most common cause of chronic kidney disease (CKD) and kidney failure. Diabetic nephropathy affects approximately $20-40 \%$ of individuals who have diabetes [1], making it one of the most common complications related to diabetes. Screening for diabetic nephropathy along with early intervention is fundamental to delaying its progression in conjunction with providing proper glycemic control. Given the growing population that is now affected by diabetes and thus, nephropathy, knowledge regarding the safe use of various anti-hyperglycemic agents in those with nephropathy is of importance. In addition, attention to modification of cardiovascular disease (CVD) risk factors is essential. Altogether, knowledge regarding the prevention and management of diabetic nephropathy, along with other aspects of diabetes care, is part of the comprehensive care of any patient with diabetes.

\section{Review}

Recommendations for nephropathy screening in diabetes Patients with diabetes should be screened on an annual basis for nephropathy. In individuals with type 1 diabetes, screening for nephropathy should start 5 years after

\footnotetext{
* Correspondence: molitch@northwestern.edu

Division of Endocrinology, Metabolism, and Molecular Medicine,

Northwestern University Feinberg School of Medicine, 645 N. Michigan

Avenue, Suite 530, 60611 Chicago, Illinois, USA
}

diagnosis of diabetes since the onset of diabetes itself is usually known. It typically takes about 5 years for microvascular complications to develop. In patients with type 2 diabetes, screening should begin at initial diagnosis since the exact onset of diabetes is often unknown [1].

Diabetic nephropathy can be detected by the measurement of urine albumin or serum creatinine, and both tests should be performed at minimum annually [1]; those with abnormal levels should have repeat tests done sooner. The first stage of nephropathy is usually the onset of elevated urine albumin which predicts the development of CKD and a gradual decline in glomerular filtration rate (GFR). Some individuals with CKD, however, do not develop elevated urine albumin initially. It is therefore important that individuals have both blood and urine screening tests performed. Using both modalities allows for identification of more cases of nephropathy than using either test alone.

The urine albumin to creatinine ratio can be measured on a spot or timed urine collection such as 4 or $24 \mathrm{~h}$. Microalbuminuria is defined as $>30 \mathrm{mg} / \mathrm{g}$ creatinine or $30 \mathrm{mg}$ per $24 \mathrm{~h}$. Clinical-or macro-albuminuria is defined as $>300 \mathrm{mg} / \mathrm{g}$ creatinine or $300 \mathrm{mg}$ per $24 \mathrm{~h}$. An abnormal value should be confirmed on at least one additional urine specimen over a 6 month period. Recently, the terms "moderately increased" and "severely increased" albuminuria have been introduced to replace the terms "microalbuminuria" and "macroalbuminuria". 
Increased albumin excretion is not only a marker for early diabetic kidney disease but also for increased risk for macrovascular disease [1]. Other causes of elevated urine protein should be considered and avoided such as infection, strenuous exercise, hypertension, heart failure and hematuria. The serum creatinine should be used to estimate GFR and thus, the level of CKD.

One must also consider that the development of nephropathy may not be related to the diabetes itself. In patients with type 1 diabetes, the onset of retinopathy usually precedes the development of nephropathy. An individual who present with nephropathy but no retinopathy should have an evaluation for other causes. Referral to a nephrologist should be utilized to establish the cause of nephropathy when this is uncertain. $\mathrm{Ne}$ phrologists are also vital to assist management of complications of advancing kidney disease, such as difficult to control hypertension, hyperkalemia and rapid progression $[1,2]$.

\section{Glycemic control in CKD}

Glycemic control is essential to delay the onset of complications from diabetes, and it can be challenging for even the most experienced physician. Blood sugar control in those with CKD adds another level of complexity. It requires detailed knowledge of which medications can be safely used and how kidney disease affects metabolism of these medications. In addition, the glycemic target needs to be individualized for each patient, acknowledging that our ability to interpret the data can be altered in the setting of kidney disease.

\section{Glycemic goal to attain A1c 7.0 \%}

Glycemic control is essential to delay or possibly prevent nephropathy. In general, the recommended target A1c for diabetes control by the ADA has been less than or around $7 \%$ [3]. The ADA advises both higher $(<8 \%)$ or stricter $(<6.5 \%)$ A1c goals for certain populations [3]. AACE suggests a goal A1c of $\leq 6.5 \%$ in healthy patients who are at low risk for hypoglycemia but also acknowledges the goals need to be individualized [4]. The 2007 Kidney Disease Outcomes Quality Initiative (KDOQI) guidelines for Diabetes and CKD endorse a target A1c of $<7.0 \%$ [2] but their updated 2012 guidelines instead recommend an A1c of 7.0 \% [5].

In type 1 diabetes, a number of studies show the development of microalbuminuria is associated with poorer glycemic control. In the DCCT, intensive therapy in patients with type 1 diabetes (mean A1c $9.1 \%$ vs. $7.2 \%)$ reduced the occurrence of microalbuminuria by $34 \%$ in the primary prevention group and $43 \%$ in the secondary intervention group (who had known early complications at baseline); risk reduction in progression to clinical albuminuria was also seen $[6,7]$. To assess whether risk reduction of diabetic nephropathy persists long-term, the EDIC Study demonstrated there were fewer cases of new microalbuminuria and progression to albuminuria in the original intensive group. In this longterm follow-up study of the original DCCT treatment groups, it was shown that intensive treatment did result in a significant decrease in the development of estimated GFR levels of $<60 \mathrm{ml} / \mathrm{min} / 1.73 \mathrm{~m}^{2}$ [8]. In patients with type 2 diabetes, the Kumamoto study, UKPDS and Veterans Affairs Cooperative studies showed reduction of new onset nephropathy and progression of nephropathy with intensive glycemic control [9-11]. A systematic review and meta-analysis of 7 trials evaluating intensive glucose control on kidney-related end points in patients with type 2 diabetes showed lower risk of developing microalbuminuria and macroalbuminuria. The intensive control groups had a median A1c ranging from 6.4$7.4 \%$. The A1c difference in the intensive groups compared to the control groups ranged from $0.6-2.3 \%$, with 4 of the studies demonstrating an A1c difference of more than $1 \%$. The analysis also found there was no benefit in regards to doubling of serum creatinine, development of ESRD or death related to kidney disease [12].

The ACCORD study showed higher risk of hypoglycemia and mortality in patients with type 2 diabetes treated with intensive glucose control (mean A1c $6.4 \%$ vs. $7.5 \%$ ), without any risk reduction on CVD. The increased mortality could not be attributed to hypoglycemia [13]. In the ADVANCE trial, more intensive glycemic control (A1c $6.5 \%$ vs. $7.3 \%$ ) showed no reduction in CVD. However, the intensive group had a $21 \%$ reduction in nephropathy [14]. The VADT study (intensive group with A1c $6.9 \%$ vs. $8.4 \%$ ) also showed no benefit on CVD risk with stricter glucose control [15].

The data clearly show that lowering A1c leads to benefit in regards to nephropathy. Benefits in A1c reduction are also seen on rates of retinopathy and neuropathy. However, the effect of lowering A1c is much less in regards to macrovascular disease. Thus, it is reasonable that a target A1c $~ 7.0 \%$ offers an optimal risk to benefit ratio rather than a target that is considerably lower.

\section{Glycemic goal in CKD}

Lower A1c levels are associated with higher risk of hypoglycemia which necessitates tailored A1c targets for different individuals. Consequences of hypoglycemia, which in turn can cause injury, myocardial infarction, seizure, stroke or death, are greatest in those who are frail and elderly, with erratic eating habits, on insulin and sulfonylureas, and with CKD. Higher A1c targets should be considered for those with shortened life expectancies, a known history of severe hypoglycemia or hypoglycemia unawareness, CKD, as well as in children. 
The Controversies Conference on Diabetic Kidney Disease (DKD) held by KDIGO addressed a number of issues surrounding DKD, including appropriate glycemic control targets [16]. There are insufficient data and trials regarding the ideal glucose target in patients with CKD stage 3 or worse. One study showed that A1c levels $>9 \%$ and $<6.5 \%$ were associated with increased mortality in the presence of non-dialysis dependent CKD stage 3 or worse [17]. ESRD patients with diabetes benefit from maintaining their A1c between 7-8 \%, as A1c levels above $8 \%$ or below $7 \%$ carry increased risks of all-cause and cardiovascular death $[18,19]$. A recent observational study found patients who started dialysis at a younger age ( $<60$ years old) had poorer survival with A1c $>8.5 \%$ (HR 1.5 compared to those with A1c 6.5$7.4 \%)$; there was no difference in older patients [20].

\section{Accuracy of A1c}

The hemoglobin A1c can be inaccurate in some patients with kidney disease. Contributing factors include anemia from reduced lifespan of the red blood cell, hemolysis and iron deficiency; falsely increased levels can occur from carbamylation of hemoglobin and the presence of acidosis. Fructosamine and glycated albumin are alternative measures available to estimate glycemic control. Fructosamine reflects the glycation of multiple serum proteins whereas glycated albumin reflects glycation of only albumin; both provide an estimate of control over the past 2 weeks. It is unclear if they offer superior measures of glucose control compared to A1c in patients with CKD. Some studies suggest glycated albumin is superior to $\mathrm{A} 1 \mathrm{c}$ in dialysis patients since A1c tends to underestimate glycemic control in those with ESRD, but others argue that A1c remains the gold standard in these patients [21-23].

\section{Medical therapy in diabetic nephropathy}

Medical therapy for diabetes is continually changing as new therapies become available for use and new updates are available that add to our knowledge of the safety profile of available medications. Please refer to Table 1 for adjustments in dosing for diabetes medications used in CKD.

\section{Insulin}

Patients with progression of kidney disease are at increased risk of hypoglycemia due to decreased clearance of insulin and some medications used to treat diabetes as well as impairment of renal gluconeogenesis from lower kidney mass. The kidney is responsible for about 30 to $80 \%$ of insulin removal; reduced kidney function is associated with a prolonged insulin half-life and a decrease in insulin requirements as GFR declines [24].
All available insulin preparations can be used in patients with CKD, and there is no specified advised reduction in dosing for patients on insulin. The insulin type, dose and administration must be tailored to each patient to achieve goal glycemic levels but limit hypoglycemia. An inpatient study randomizing weight-based basal and bolus insulin in patients with a GFR $<45 \mathrm{~mL} / \mathrm{min} /$ $1.73 \mathrm{~m}^{2}$ to 0.5 units $/ \mathrm{kg}$ body weight vs. 0.25 units $/ \mathrm{kg}$ showed similar glycemic control but significantly less hypoglycemia in the group with the lower weight-based dose [25].

The rapid-acting insulin analogs aspart, lispro and glulisine are the quickest absorbed and are ideal for rapid correction of elevated blood sugars or for prandial insulin needs; they most resemble physiologic insulin secretion. They have an onset of action at 5-15 min, peak action at 30-90 min and an average duration of $5 \mathrm{~h}$. Some studies have shown glulisine has a slightly longer duration of action than the other two rapid-acting insulins. These insulins can be given up to 15 min prior to eating. They are used in "basal-bolus therapy", also known as multiple daily injections (MDI), as well as in continuous subcutaneous insulin infusions, also known as insulin pumps. The approximate retail cost per vial is \$150-165 [26].

Patients with Stage 4-5 CKD and those on dialysis often have some delayed gastric emptying; giving rapidacting insulin after the meal may be helpful for matching the insulin peak with the time of the postprandial blood glucose peak. In patients with nausea who may not know how much they will eat, postprandial rapidacting insulin dosing may be worth trying. Similarly, patients on peritoneal dialysis obtain large amounts of calories from their dialysis fluid and often eat less than they might expect so that postprandial dosing may be helpful for them also.

The short-acting insulin available is regular crystalline insulin, which has an onset of action at 30-60 min, peak action at $2-3 \mathrm{~h}$ and duration up to $5-8 \mathrm{~h}$. Regular insulin should ideally be given $30 \mathrm{~min}$ prior to a meal. The main advantage of regular insulin is its substantially lower cost compared to the rapid-acting analogs. Regular insulin costs about $\$ 90$ per vial [26].

The available intermediate-acting insulin is isophane, or NPH. It has an onset of action at 2-4 h, peak concentration at 4-10 $\mathrm{h}$ and duration up to $10-18 \mathrm{~h}$. In order to achieve adequate basal coverage, it is dosed twice daily. Its use can be limited by its highly variable absorption. Its cost is similar to that of Regular insulin.

The long-acting insulin analogs are glargine and detemir. Glargine has an onset of action at $2-4 \mathrm{~h}$, with minimal peak and duration of $20-24 \mathrm{~h}$; it is usually dosed once daily. A unique property of glargine is that it does not have a clear peak. Detemir has an onset of 
Table 1 Dose adjustment for insulin compounds and medications for diabetes in CKD

\begin{tabular}{ll}
\hline Medication class & CKD stages 3 and 4 and predialysis stage 5 \\
\hline Insulin & No advised dose adjustment* \\
Detemir & No advised dose adjustment* \\
NPH & No advised dose adjustment* \\
Regular & No advised dose adjustment* \\
Aspart & No advised dose adjustment* \\
Lispro & No advised dose adjustment* \\
Glulisine & No advised dose adjustment*
\end{tabular}

First-generation

sulfonylureas

$\begin{array}{ll}\begin{array}{ll}\text { Acetohexamide** } \\ \text { Chlorpropamide }\end{array} & \text { Avoid use } \\ & \text { eGFR 50-80: reduce dose by } 50 \% \\ \text { Tolazamide } & \text { Avoid use } \\ \text { Tolbutamide } & \text { Avoid use } \\ \begin{array}{l}\text { Second-generation } \\ \text { sulfonylureas }\end{array} & \\ \text { Glipizide } & \text { eGFR <30: use with caution } \\ \text { Glimepiride } & \text { eGFR <60: use with caution } \\ & \text { eGFR <30: avoid use } \\ \text { Glyburide } & \text { Avoid use } \\ \text { Gliclazide } & \text { No dose adjustment } \\ \text { Glinides } & \\ \text { Repaglinide } & \text { No dose adjustment but may wish to use } \\ \text { Nateglinide } & \text { caution with eGFR <30 } \\ & \text { eGFR <60: avoid use (but may consider } \\ & \text { use if patient is on hemodialysis) }\end{array}$

Biguanides

Metformin***

Thiazolidinediones

$\begin{array}{ll}\text { Pioglitazone } & \text { No dose adjustment } \\ \text { Rosiglitazone } & \text { No dose adjustment }\end{array}$

Alpha-glucosidase inhibitors

Acarbose
Miglitol
DP-4 inhibitor
Sitagliptin

Per FDA, do not use if serum $\mathrm{Cr} \geq 1.5 \mathrm{mg} / \mathrm{dL}$ in $\mathrm{men} \geq 1.4 \mathrm{mg} / \mathrm{dL}$ in women.

\section{Consider}

eGFR $\geq 45-59$ : use caution with dose and follow renal function closely (every 3-6 months)

eGFR $\geq 30-44$ : max dose $1000 \mathrm{mg} /$ day or use $50 \%$ dose reduction. Follow renal function every 3 months. Do not start as new therapy.

eGFR <30: avoid use

No dose adjustment

serum $\mathrm{Cr}>2 \mathrm{mg} / \mathrm{dl}$ : avoid use

eGFR $<25$ or serum $\mathrm{Cr}>2 \mathrm{mg} / \mathrm{dl}$ : avoid use

eGFR $\geq 50$ : 100 mg daily
Table 1 Dose adjustment for insulin compounds and medications for diabetes in CKD (Continued)

\begin{tabular}{|c|c|}
\hline & eGFR 30-49: 50 mg daily \\
\hline & eGFR < 30: 25 mg daily \\
\hline \multirow[t]{2}{*}{ Saxagliptin } & eGFR > 50: 2.5 or 5 mg daily \\
\hline & GFR $\leq 50: 2.5$ mg daily \\
\hline Linagliptin & No dose adjustment \\
\hline \multirow[t]{3}{*}{ Alogliptin } & eGFR >60: 25 mg daily \\
\hline & eGFR 30-59: 12.5 mg daily \\
\hline & eGFR <30: 6.25 mg daily \\
\hline \multicolumn{2}{|l|}{ SGLT2 inhibitors } \\
\hline \multirow[t]{2}{*}{ Canagliflozin } & eGFR 45 to <60: max dose 100 mg once daily \\
\hline & eGFR $<45$, avoid use \\
\hline Dapagliflozin & eGFR $<60$, avoid use \\
\hline Empagliflozin & eGFR $<45$, avoid use \\
\hline \multicolumn{2}{|c|}{$\begin{array}{l}\text { Dopamine receptor } \\
\text { agonist }\end{array}$} \\
\hline $\begin{array}{l}\text { bromocriptine } \\
\text { mesylate }\end{array}$ & $\begin{array}{l}\text { No dose adjustment known but not studied: } \\
\text { use with caution }\end{array}$ \\
\hline \multicolumn{2}{|l|}{$\begin{array}{l}\text { Bile acid } \\
\text { sequestrant }\end{array}$} \\
\hline Colesevelam & No dose adjustment known but limited data \\
\hline \multicolumn{2}{|l|}{ GLP-1 Agonists } \\
\hline \multirow[t]{2}{*}{ Exenatide } & eGFR 30-50: use caution \\
\hline & eGFR <30: avoid use \\
\hline Liraglutide & $\begin{array}{l}\text { No dose adjustment but use caution when } \\
\text { starting or titrating the dose }\end{array}$ \\
\hline Albiglutide & No dose adjustment needed \\
\hline Dulaglutide & No dose adjustment needed \\
\hline \multicolumn{2}{|l|}{ Amylin analog } \\
\hline Pramlintide & $\begin{array}{l}\text { No dose adjustment known but not studied } \\
\text { in ESRD }\end{array}$ \\
\hline
\end{tabular}

\section{*Adjust dose based on patient response \\ **Not available in the U.S. \\ ***Recommendations are controversial}

action at $1-3 \mathrm{~h}$, with a small peak at $6-8 \mathrm{~h}$ and duration of action of 18-22 h. Detemir is dosed twice daily to give adequate basal coverage in type 1 diabetes; in type 2 diabetes, once daily dosing sometimes is sufficient. The approximate retail price is $\$ 160-190$ per vial for determir and glargine insulins [26].

There are various premixed preparation of insulin that have a fixed percentage of an intermediate-acting and a rapid-or short-acting insulin. Because they contain a combination of 2 insulins, they have two separate peaks. One example is "70/30" which is $70 \% \mathrm{NPH}$ and $30 \%$ regular insulin. These preparations offer convenience for the patient with twice daily dosing but offer less flexibility and more restrictions in titration of the insulin. It must be taken at fixed times and the patient must 
have consistent meals. 70/30 insulin is sometimes helpful in patients getting 12-hours cycled tube feeds.

All insulin is U-100, which is defined as 100 units of insulin $/ \mathrm{ml}$. The exception is insulin U-500 which is 500 units of insulin $/ \mathrm{ml}$ and is only available as regular insulin. The high concentration of U-500 insulin alters the properties of regular insulin so its pharmacokinetics are different. It has a similar onset of action, near $30 \mathrm{~min}$, but the peak is at $4-8 \mathrm{~h}$ and duration is $14-15 \mathrm{~h}$. It can be given up to $30 \mathrm{~min}$ prior to meals and is typically given two to three times daily, without the use of a basal insulin [27]. It is generally used in patients who are severely insulin resistant and can be used as a subcutaneous injection or in a pump.

\section{Oral medications}

\section{Metformin}

Metformin increases insulin sensitivity and decreases hepatic gluconeogenesis; it does not cause hypoglycemia and may lead to weight loss in some patients. It reduces A1c by $1.0-2.0 \%$ [28]. The most common side effects are diarrhea, bloating and cramping. Vitamin B12 deficiency has been reported with extended use [29]. The estimated cost for metformin is about $\$ 50$ for one month of the $500 \mathrm{mg}$ dose [26].

The FDA recommends that metformin should not be used with serum creatinine $\geq 1.5 \mathrm{mg} / \mathrm{dl}$ in men and $\geq$ $1.4 \mathrm{mg} / \mathrm{dl}$ in women or with decreased creatinine clearance in people over age 80 . Because metformin is renally cleared, this recommendation is in place to reduce the risk of lactic acidosis in individuals with even modest renal impairment [30]. The overall incidence of lactic acidosis with metformin use, however, appears to be rare. A Cochrane database review of 347 prospective trials and observational cohort studies showed no cases of fatal or non fatal lactic acidosis in 70,490 patientyears of metformin users or in 55,451 patient-years of users of other anti-hyperglycemic agents [31]. In a study evaluating metformin-associated lactic acidosis in 14 patients, other causes of lactic acidosis (including clinical shock or tissue hypoxia) were noted and seemed to be the driving cause and not specifically metformin; 10 of these patients did have metformin accumulation related to elevated serum creatinine (range $3.05-11.8 \mathrm{mg} / \mathrm{dl}$ ) whereas 4 patients, all with lower creatinine levels though still reduced GFR, had no evidence of metformin accumulation [32].

Given the differences in translation of creatinine into creatinine clearance based on age, weight and race, it is reasonable to consider use of a GFR-based guideline such as outlined here rather than one based on creatinine alone. Metformin can be used without dose reduction with an eGFR $>60 \mathrm{ml} / \mathrm{min} / 1.73 \mathrm{~m}^{2}$. If the eGFR is $\geq 45-59 \mathrm{ml} / \mathrm{min} / 1.73 \mathrm{~m}^{2}$, it is prudent to continue use of metformin but take caution with dosing and follow the renal function more closely, such as every 3 to 6 months. If the eGFR is $\geq 30-44 \mathrm{ml} / \mathrm{min} / 1.73 \mathrm{~m}^{2}$, again use caution with dosing, such as limiting its dose to a maximum of $1000 \mathrm{mg}$ daily or using a $50 \%$ reduction, follow renal function every 3 months and avoid newly initiating metformin in patients with this level of CKD. Metformin should be avoided with eGFR $<30 \mathrm{ml} / \mathrm{min} / 1.73 \mathrm{~m}^{2}$. It is recommended that metformin be stopped in the presence of situations that are associated with hypoxia or an acute decline in kidney function such as sepsis/shock, hypotension, acute myocardial infarction, and use of radiographic contrast or other nephrotoxic agents [33, 34]. This approach has been accepted by various societies including KDIGO and confirmed in additional studies [35] [36]. The KDIGO Controversies Conference proposed a change to the FDA guidelines [16].

\section{Sulfonylureas}

Sulfonylureas bind to the sulfonylurea receptor on the pancreatic beta-cells and lead to increased insulin secretion. They typically lower A1c by $1.5-2 \%$ and can cause hypoglycemia. The first-generation sulfonylureas are rarely prescribed. The second-generation sulfonylureas, which include glipizide, glimepiride, glyburide, and gliclazide (the latter is not available in the U.S.), are commonly used. The sulfonylureas will decrease A1c by $1-$ $2 \%$ [28]. The estimated cost for one month of glipizide and glyburide $(5 \mathrm{mg}$ ) and glimepiride $(2 \mathrm{mg})$ ranges from $\$ 10$ to $\$ 30$ [26].

Sulfonylureas and their metabolites are renally cleared, leading to an increased risk of hypoglycemia as GFR declines. Hypoglycemia is greatly increased with glimepiride and glyburide with GFR $<60 \mathrm{ml} / \mathrm{min} / 1.73 \mathrm{~m}^{2}$ due to the presence of two active metabolites cleared in part by the kidney [37]. Glyburide should be avoided with eGFR $<60 \mathrm{ml} / \mathrm{min} / 1.73 \mathrm{~m}^{2}$ [38]. Glimepiride should be used with caution if the eGFR is $<60 \mathrm{ml} / \mathrm{min} / 1.73 \mathrm{~m}^{2}$ and not be used with eGFR $<30 \mathrm{ml} / \mathrm{min} / 1.73 \mathrm{~m}^{2}$ [37]. Less than $10 \%$ of glipizide is cleared renally but it should still be used with caution with an eGFR $<30 \mathrm{ml} / \mathrm{min} / 1.73 \mathrm{~m}^{2}$ due to the risk of hypoglycemia $[39,40]$.

\section{Glinides}

Nateglinide and repaglinide, like sulfonylureas, increase insulin secretion by closing a sulfonylurea receptor/ ATP-dependent potassium channel on the beta-cells of the pancreas. They have a shorter half-life compared to the sulfonylureas. They result in a rapid and short duration of insulin release and should be taken prior to meals. They also can cause hypoglycemia [41]. The glinides reduce A1c on average by $0.5-1.5 \%$ [28] and have an estimated cost of $\$ 90$ per month (for repaglinide $1 \mathrm{mg}$, and $\$ 60$ per month for nateglinide $120 \mathrm{mg}$ ) [26]. 
The active metabolite of nateglinide accumulates in CKD; nateglinide should not be used with an eGFR $<60 \mathrm{ml} / \mathrm{min} / 1.73 \mathrm{~m}^{2}$. The active metabolite is cleared, however, by hemodialysis so nateglinide can be used in those undergoing dialysis [42]. Conversely, repaglinide appears safe to use in individuals with CKD [43]. However, it is reasonable to exercise caution in those with more severe renal dysfunction, such as an eGFR $<30 \mathrm{ml} /$ $\min / 1.73 \mathrm{~m}^{2}$, and start at the lowest dose $(0.5 \mathrm{mg})$ with slow upwards titration.

\section{Thiazolidinediones}

Thiazolidinediones (pioglitazone, rosiglitazone) increase insulin sensitivity by acting as PPAR $\gamma$ agonists. They do not cause hypoglycaemia and they lead to an A1c decrease of $0.5-1.4 \%$ [28]. They are metabolized by the liver and can be used in CKD. However, fluid retention is a major limiting side effect and they should not be used in advanced heart failure. This also makes their use in CKD, particularly patients on dialysis, limiting. They have been linked with increased fracture rates and bone loss, thus use in patients with underlying bone disease (such as renal osteodystrophy) needs to be considered. No dose adjustment is indicated with either in CKD. One month of $15 \mathrm{mg}$ of pioglitazone costs about $\$ 260$ and $2 \mathrm{mg}$ of rosiglitazone costs about $\$ 100$ [26]. In September 2010, the FDA restricted use of rosiglitazone based on studies linking it to increased cardiovascular events. Upon further review, these restrictions were lifted in 2014.

An association between pioglitazone and bladder cancer has been raised but further analysis and investigation into the data shows that this association is not clearly supported [44]. A recent pooled multi-population analysis also showed no association between the thiazolidinediones and bladder cancer [45].

\section{Alpha-glucosidase inhibitors}

Alpha-glucosidase inhibitors (acarbose, miglitol) decrease the breakdown of oligo-and disaccharides in the small intestine, slowing ingestion of carbohydrates and delaying absorption of glucose after a meal. The major side effects are bloating, flatulence, and abdominal cramping. They typically lower A1c by $0.5-0.8 \%$ and usually do not lead to weight gain or loss [28]. The approximate cost for one month of $25 \mathrm{mg}$ of either dose is about $\$ 30$ (acarbose) to $\$ 250$ (miglitol) [26].

Acarbose is minimally absorbed with $<2 \%$ of the drug and active metabolites present in the urine. With reduced renal function, serum levels of acarbose and metabolites are significantly higher. Miglitol has greater systemic absorption with $>95 \%$ renal excretion. It is recommended that use of miglitol be avoided if the GFR is $<25 \mathrm{ml} / \mathrm{min} / 1.73 \mathrm{~m}^{2}$ [46]. Additionally, neither medication has been studied long-term in patients with a creatinine $>2 \mathrm{mg} / \mathrm{dl}$, so their use should be avoided in these patients.

\section{Dipeptidyl peptidase-4 inhibitors}

Dipeptidyl peptidase 4 (DPP 4) inhibitors decrease the breakdown of incretin hormones such as GLP-1 and include sitagliptin, saxagliptin, linagliptin, and alogliptin. This class of medication is weight-neutral and decreases A1c by $0.5-0.8 \%$ [28]. One month of $50 \mathrm{mg}$ sitaglipitin or $5 \mathrm{mg}$ saxagliptin is about $\$ 280$ [26].

Approximately $80 \%$ of sitagliptin is cleared by the kidney; with an eGFR of $\geq 30$ to $<50 \mathrm{ml} / \mathrm{min} / 1.73 \mathrm{~m}^{2}$, $50 \mathrm{mg}$ once daily should be used and with an eGFR $<30 \mathrm{ml} / \mathrm{min} / 1.73 \mathrm{~m}^{2}$, a dose of $25 \mathrm{mg}$ once daily isadvised [47]. Saxagliptin also needs a dose reduction with $\mathrm{eGFR} \leq 50 \mathrm{ml} / \mathrm{min} / 1.73 \mathrm{~m}^{2}$ to $2.5 \mathrm{mg}$ daily; otherwise, the standard dose with eGFR $>50 \mathrm{ml} / \mathrm{min} /$ $1.73 \mathrm{~m}^{2}$ is 2.5 or $5 \mathrm{mg}$ daily. Only a small amount of linagliptin is cleared renally; thus, no dose adjustment is indicated with a reduced GFR [48]. Alogliptin also needs a dose reduction from the baseline dose of $25 \mathrm{mg}$ daily to $12.5 \mathrm{mg}$ daily with an eGFR $<60 \mathrm{ml} / \mathrm{min} / 1.73 \mathrm{~m}^{2}$ and then to $6.25 \mathrm{mg}$ daily with an eGFR $<30 \mathrm{ml} / \mathrm{min} / 1.73 \mathrm{~m}^{2}$.

\section{Sodium-glucose co-transporter 2 (SGLT2) inhibitors}

SGLT2 inhibitors reduce glucose absorption from the kidney, leading to an increase in glucose excretion and a reduction in A1c of about $0.9-1.0 \%$ [49]. The increase in urine glucose can result in a weight loss of up to $5 \mathrm{~kg}$ in one year. Because of an increase in adverse events related to intravascular volume contraction, no more than $100 \mathrm{mg}$ once daily of canagliflozin should be used in patients with an eGFR of 45 to $<60 \mathrm{ml} / \mathrm{min} /$ $1.73 \mathrm{~m}^{2}$. Its use should be avoided if the eGFR is $<45 \mathrm{ml} / \mathrm{min} / 1.73 \mathrm{~m}^{2}$ because of an increase in adverse events as well as reduced efficacy. Dapagliflozin is not approved for use if the eGFR is $<60 \mathrm{ml} / \mathrm{min} / 1.73 \mathrm{~m}^{2}$ but empagliflozin can be used down to an eGFR of $45 \mathrm{ml} / \mathrm{min} / 1.73 \mathrm{~m}^{2} \mathrm{ml} / \mathrm{min} / 1.73 \mathrm{~m}^{2}$. Costs for 30 days of the lowest doses of these drugs are in the \$350-400 range.

\section{Other oral medications}

Bromocriptine (dopamine receptor agonist) has not been adequately studied in CKD.

Colesevelam (bile acid sequestrant) shows no difference in efficacy or safety in those with an eGFR $<50 \mathrm{ml} /$ $\mathrm{min} / 1.73 \mathrm{~m}^{2}$ but data are limited as it has not been adequately studied in more advanced CKD. A one month supply of the $625 \mathrm{mg}$ tablets ( 6 tablets per day must be taken) is about $\$ 420$. 


\section{Other subcutaneous medications}

\section{Glucagon-like peptide 1 (GLP-1) Receptor Agonists}

Exenatide (regular and extended-release) and liraglutide are injectable medications that mimic gut hormones known as incretins, leading to insulin release, delayed glucagon secretion and delayed gastric emptying. They are FDA approved for use with metformin and/or sulfonylureas although in practice, they are also used with insulin. They contribute to central satiety leading to a reduction in appetite and often weight loss. The average expected A1c decrease is $0.5-1.0 \%$ [28]. The costs of exenatide regular-release is about $\$ 385$ for a $10 \mathrm{mcg}$ pen and $\$ 596$ for 3 pens of the liraglutide [26]. Both agents have been associated with pancreatitis, and nausea is a common side effect that can limit its use. In addition, liraglutide has been associated with the development of thyroid C-cell tumors in animal studies and thus should not be given to patients with or at risk for medullary thyroid cancer. Exenatide is given twice daily and liraglutide is given once daily; exenatide extended-release is dosed once weekly. Albiglutide and dulaglutide are other GLP-1 receptor agonists that can also be dosed once weekly.

Clearance of exenatide decreases with declines in GFR [50]. Additionally, in a case report of a patient with renal impairment and CKD, use of exenatide led to a rise in serum creatinine that resolved when the medication was stopped [51]. The FDA reported cases of acute renal failure associated with exenatide use and recommends it be used with caution in those with a GFR of $30-50 \mathrm{ml} /$ $\mathrm{min} / 1.73 \mathrm{~m}^{2}$ and not be used if the GFR is $<30 \mathrm{ml} / \mathrm{min} /$ $1.73 \mathrm{~m}^{2}$ [52]. Liraglutide is not metabolized primarily by the kidney; no dose adjustment is indicated in those with renal impairment, including ESRD, although data in this population are limited [53]. No dosage restrictions are needed for albiglutide or dulaglutide with decreasing GFR [54, 55]. The manufacturer has reported cases of renal failure and worsening of chronic renal impairment with its use and advises caution with initiating or increasing the dose in those with nephropathy.

\section{Amylin analog}

Pramlintide is also an injectable medication that is used with meals as an adjunct to insulin therapy in both type 1 and type 2 diabetes. Amylin is secreted along with insulin by pancreatic beta-cells and levels are low in patients with diabetes. It typically reduces A1c by $0.5-1.0 \%$ [28] with a cost of about $\$ 400$ for two of the $1.5 \mathrm{~mL}$ pens $(1000 \mathrm{mcg} /$ $\mathrm{mL}$ ) [26]. No dose adjustment appears necessary for CKD; it has not been studied in ESRD.

\section{Strategy for glycemic control and other risk factors}

The primary goal of optimizing glycemic control to reduce the development of microvascular and macrovascular complications is universal. The medication regimen is based on the comfort of the patient and physician and should be individualized, especially as renal function changes.

For those who need insulin, MDI with an average of 4 daily injections is common. The closest approximation of physiologic insulin secretion can be achieved with an insulin pump delivering a continuous subcutaneous infusion. A single type of insulin is used in the pump such as a rapid-acting analog that serves as the basal, bolus and correction insulin. Insulin pumps require vigilance on the part of the patient and their use should be overseen by endocrinologists and experienced diabetes educators.

Continuous Glucose Monitoring Systems (CGMS) are available that can continually measure glucose levels. A small plastic catheter is inserted subcutaneously and measures glucose every $5 \mathrm{~min}$. Patients can view this in real-time and detect upward and downward trends in glucose. The added benefit is that alarms for high and low readings can be set.

In addition to glucose control, a comprehensive approach to care is encouraged. Behavioral modification and lifestyle changes are important to control weight, improve nutrition, modify dietary intake and monitor glucose levels. Appropriate medication should be used for treatment of nephropathy, in conjunction with a nephrologist as appropriate. Close attention should also be paid to blood pressure control. Diabetes in itself is a major cause of cardiovascular disease and individuals with CKD often die of CVD; it is the major cause of death in this population. The presence of microalbuminuria, albuminuria and declining GFR are all known predictors of CVD. The combination of diabetes and CKD is particularly powerful in regards to CVD risk, necessitating aggressive control of risk factors [56]. In addition to hypertension, dyslipidemia and weight control should be addressed. Nutrition plays an important role in individuals with diabetic kidney disease as a balance of multiple dietary factors including sodium, potassium, phosphorus, and protein intake must be followed as well as intake of carbohydrates and unhealthy fats. Reduction in weight in patients who are overweight or obese and increases in exercise are generally recommended, keeping in mind the need for cardiac stress testing. It is helpful to use an experienced dietician and certified diabetes educator to safely attain dietary, exercise and weight loss goals. The KDIGO Controversies Conference addresses some of the issues surrounding diabetic kidney disease management including management of dyslipidemia and blood pressure control [16]. The American Diabetes Association also has recommendations on management of blood pressure and dyslipidemia [57]. 


\section{Medical therapy in dialysis and post-transplant patients}

There are a few oral agents that can be used safely in patients on dialysis, particularly if the diabetes is fairly mild. Most others, however, will need insulin for glycemic control.

Patients receiving hemodialysis (HD) can have different clearance rates of insulin that may be affected by the timing of dialysis. We have done continuous glucose monitoring on patients undergoing $\mathrm{HD}$ and found that patients' glycemic responses during HD are quite idiosyncratic and their insulin regimens need to be individualized to avoid both hyper-and hypoglycemia during and after HD. Patients who are on peritoneal dialysis (PD) have exposure to large amounts of glucose in the dialysate that can lead to uncontrolled hyperglycemia. In patients receiving PD continuously, a standard basal/bolus insulin regimen is best. However, with overnight PD using a cycler, coverage of the increased glucose load may best be accomplished using a fixed mixture insulin combination, such as $70 / 30$ or $75 / 25$ insulins, given at the onset of PD. The nephrologist prescribing the PD will often change the glucose concentration of the dialysate because of the need for more or less fluid removal and such changes need to be discussed with the endocrinologist so that the insulin doses may be appropriately changed.

In the immediate post-transplant period, glycemic control can acutely decline. This is due to the initiation of anti-rejection therapies including glucocorticoids, calcineurin inhibitors and sirolimus, and an increase in insulin resistance. In addition, patients may experience other fluctuations in their daily routines including adjustments in diet, activity and medications. Because many variables are present, glycemic control can fluctuate quite a bit, and close monitoring of blood glucose levels and adjustments of medications are needed.

\section{Conclusions}

The management of patients with diabetes and nephropathy necessitates attention to several aspects of care. Importantly, glycemic control should be optimized for the patient, attaining the necessary control to reduce complications but done in a safe, monitored manner. Screening for development of nephropathy should be performed on a regular basis to identify microalbuminuria or reductions in GFR and if identified, the diabetes regimen should be tailored accordingly. Prevention and treatment of diabetic nephropathy and other complications necessitates a multifactorial approach through the use of a diabetologist, nephrologist, dietician, diabetes educator and additional specialists experienced in the complications of diabetes to provide a multifaceted care program to reduce progression of disease.

\section{Abbreviations}

CKD: Chronic kidney disease; CVD: Cardiovascular disease; GFR: Glomerular filtration rate; DKD: Diabetic kidney disease; MDI: Multiple daily injections; CSII: Continuous subcutaneous insulin infusion; DPP4: Dipeptidyl peptidase-4 inhibitors; SGLT2: Sodium-glucose co-transporter 2; GLP1: Glucagon-like peptide 1; HD: Hemodialysis; PD: Peritoneal dialysis.

\section{Competing interests}

The authors declare that they have no competing interests.

\section{Authors' contributions}

$\mathrm{AH}$ and MM participated in the organization of the manuscript and drafted the manuscript. Both authors read and approved the final manuscript.

Received: 6 November 2014 Accepted: 3 February 2015

Published online: 04 June 2015

\section{References}

1. ADA. Microvascular complications and foot care. Sec. 9. In standards of medical care in diabetes - 2015. Diabetes Care. 2015;38:S58-66.

2. KDOQI (Kidney Disease Outcomes Quality Initiative). Clinical practice guidelines and clinical practice recommendations for diabetes and chronic kidney disease. Am J Kidney Dis. 2007;49:S12-154.

3. ADA. Glycemic targets. Sec. 6. In standards of medical care in diabetes - 2015. Diabetes Care. 2015;38:S33-40.

4. Garber AJ, Abrahamson MJ, Barzilay Jl, Blonde L, Bloomgarden ZT, Bush MA, et al. AACE comprehensive diabetes management algorithm 2013. Endocr Pract. 2013;19:327-36.

5. KDOQI (Kidney Disease Outcomes Quality Initiative). Clinical Practice Guideline for Diabetes and CKD: 2012 Update. Am J Kidney Dis. 2012, 60:850-886.

6. DCCT. The effect of intensive treatment of diabetes on the development and progression of long-term complications in insulin-dependent diabetes mellitus. The Diabetes Control and Complications Trial Research Group. N Engl J Med. 1993;329:977-86

7. DCCT. Effect of intensive therapy on the development and progression of diabetic nephropathy in the Diabetes Control and Complications Trial. The Diabetes Control and Complications (DCCT) Research Group. Kidney Int. 1995;47:1703-20

8. EDIC. Sustained effect of intensive treatment of type 1 diabetes mellitus on development and progression of diabetic nephropathy: the Epidemiology of Diabetes Interventions and Complications (EDIC) study. JAMA 2003;290:2159-67.

9. Levin SR, Coburn JW, Abraira C, Henderson WG, Colwell JA, Emanuele NV, et al. Effect of intensive glycemic control on microalbuminuria in type 2 diabetes. Veterans Affairs Cooperative Study on Glycemic Control and Complications in Type 2 Diabetes Feasibility Trial Investigators. Diabetes Care. 2000;23:1478-85.

10. Ohkubo Y, Kishikawa H, Araki E, Miyata T, Isami S, Motoyoshi S, et al. Intensive insulin therapy prevents the progression of diabetic microvascular complications in Japanese patients with non-insulin-dependent diabetes mellitus: a randomized prospective 6-year study. Diabetes Res Clin Pract. 1995;28:103-17.

11. UKPDS. Intensive blood-glucose control with sulphonylureas or insulin compared with conventional treatment and risk of complications in patients with type 2 diabetes (UKPDS 33). UK Prospective Diabetes Study (UKPDS) Group. Lancet. 1998;352:837-53.

12. Coca SG, Ismail-Beigi F, Haq N, Krumholz HM, Parikh CR. Role of intensive glucose control in development of renal end points in type 2 diabetes mellitus: systematic review and meta-analysis intensive glucose control in type 2 diabetes. Arch Intern Med. 2012;172:761-9.

13. Gerstein HC, Miller ME, Byington RP, Goff Jr DC, Bigger JT, Buse JB, et al. Effects of intensive glucose lowering in type 2 diabetes. N Engl J Med. 2008;358:2545-59.

14. Patel A, MacMahon S, Chalmers J, Neal B, Billot L, Woodward M, et al. Intensive blood glucose control and vascular outcomes in patients with type 2 diabetes. N Engl J Med. 2008;358:2560-72.

15. Duckworth W, Abraira C, Moritz T, Reda D, Emanuele N, Reaven PD, et al. Glucose control and vascular complications in veterans with type 2 diabetes. N Engl J Med. 2009;360:129-39.

16. Molitch ME, Adler Al, Flyvbjerg A, Nelson RG, So WY, Wanner C, et al. Diabetic kidney disease: a clinical update from Kidney Disease: Improving Global Outcomes. Kidney Int. 2015;87(1):20-30. doi: 10.1038/ki.2014.128. Epub 2014 Apr 30 
17. Shurraw S, Hemmelgarn B, Lin M, Majumdar SR, Klarenbach S, Manns B, et al. Association between glycemic control and adverse outcomes in people with diabetes mellitus and chronic kidney disease: a population-based cohort study. Arch Intern Med. 2011;171:1920-7.

18. Ricks J, Molnar MZ, Kovesdy CP, Shah A, Nissenson AR, Williams M, et al. Glycemic control and cardiovascular mortality in hemodialysis patients with diabetes: a 6-year cohort study. Diabetes. 2012;61:708-15.

19. Ramirez SP, McCullough KP, Thumma JR, Nelson RG, Morgenstern H, Gillespie BW, et al. Hemoglobin A(1c) levels and mortality in the diabetic hemodialysis population: findings from the Dialysis Outcomes and Practice Patterns Study (DOPPS). Diabetes Care. 2012;35:2527-32.

20. Adler A, Casula A, Steenkamp R, Fogarty D, Wilkie M, Tomlinson L, et al. Association between glycemia and mortality in diabetic individuals on renal replacement therapy in the U.K. Diabetes Care. 2014;37:1304-11.

21. Freedman BI, Shenoy RN, Planer JA, Clay KD, Shihabi ZK, Burkart JM, et al Comparison of glycated albumin and hemoglobin A1c concentrations in diabetic subjects on peritoneal and hemodialysis. Perit Dial Int. 2010;30:72-9.

22. Kalantar-Zadeh K. A critical evaluation of glycated protein parameters in advanced nephropathy: a matter of life or death: A1C remains the gold standard outcome predictor in diabetic dialysis patients. Counterpoint. Diabetes Care. 2012;35:1625-8.

23. Freedman BI. A critical evaluation of glycated protein parameters in advanced nephropathy: a matter of life or death: time to dispense with the hemoglobin A1C in end-stage kidney disease. Diabetes Care. 2012;35:1621-4.

24. Rabkin R, Ryan MP, Duckworth WC. The renal metabolism of insulin. Diabetologia. 1984;27:351-7.

25. Baldwin D, Zander J, Munoz C, Raghu P, DeLange-Hudec S, Lee H, et al. A randomized trial of two weight-based doses of insulin glargine and glulisine in hospitalized subjects with type 2 diabetes and renal insufficiency. Diabetes Care. 2012;35:1970-4

26. Epocrates Online. https://online.epocrates.com

27. de la Pena A, Riddle M, Morrow LA, Jiang HH, Linnebjerg $H$, Scott $A$, et al. Pharmacokinetics and pharmacodynamics of high-dose human regular U-500 insulin versus human regular U-100 insulin in healthy obese subjects. Diabetes Care. 2011;34:2496-501.

28. Nathan DM, Buse JB, Davidson MB, Ferrannini E, Holman RR, Sherwin R, et al. Medical management of hyperglycemia in type 2 diabetes: a consensus algorithm for the initiation and adjustment of therapy: a consensus statement of the American Diabetes Association and the European Association for the Study of Diabetes. Diabetes Care. 2009;32:193-203.

29. Wile DJ, Toth C. Association of Metformin, Elevated Homocysteine, and Methylmalonic Acid Levels and Clinically Worsened Diabetic Peripheral Neuropathy. Diabetes Care. 2010;33:156-61.

30. Sambol NC, Chiang J, Lin ET, Goodman AM, Liu CY, Benet LZ, et al. Kidney function and age are both predictors of pharmacokinetics of metformin. J Clin Pharmacol. 1995;35:1094-102.

31. Salpeter SR, Greyber E, Pasternak GA, Salpeter EE. Risk of fatal and nonfatal lactic acidosis with metformin use in type 2 diabetes mellitus. Cochrane Database Syst Rev. 2010;14(4):CD002967.

32. Lalau JD, Lacroix C, Compagnon P, de Cagny B, Rigaud JP, Bleichner G, et al. Role of metformin accumulation in metformin-associated lactic acidosis. Diabetes Care. 1995;18:779-84.

33. Inzucchi SE, Lipska KJ, Mayo H, Bailey CJ, McGuire DK. Metformin in patients with type 2 diabetes and kidney disease: a systematic review. JAMA. 2014;312:2668-75.

34. Herrington WG, Levy JB. Metformin: effective and safe in renal disease? Int Urol Nephrol. 2008;40:411-7.

35. Eppenga WL, Lalmohamed A, Geerts AF, Derijks HJ, Wensing M, Egberts A, et al. Risk of lactic acidosis or elevated lactate concentrations in metformin users with renal impairment: a population-based cohort study. Diabetes Care. 2014;37:2218-24.

36. Richy FF, Sabido-Espin M, Guedes S, Corvino FA, Gottwald-Hostalek U. Incidence of lactic acidosis in patients with type 2 diabetes with and without renal impairment treated with metformin: a retrospective cohort study. Diabetes Care. 2014;37:2291-5.

37. Holstein A, Plaschke A, Hammer C, Ptak M, Kuhn J, Kratzsch C, et al. Hormonal counterregulation and consecutive glimepiride serum concentrations during severe hypoglycaemia associated with glimepiride therapy. Eur J Clin Pharmacol. 2003;59:747-54.

38. Holstein A, Beil W. Oral antidiabetic drug metabolism: pharmacogenomics and drug interactions. Expert Opin Drug Metab Toxicol. 2009;5:225-41.
39. Balant L, Zahnd G, Gorgia A, Schwarz R, Fabre J. Pharmacokinetics of glipizide in man: influence of renal insufficiency. Diabetologia. 1973:331-8.

40. Arjona Ferreira JC, Marre M, Barzilai N, Guo H, Golm GT, Sisk CM, et al. Efficacy and Safety of Sitagliptin Versus Glipizide in Patients With Type 2 Diabetes and Moderate-to-Severe Chronic Renal Insufficiency. Diabetes Care. 2013;36(5):1067-73. doi: 10.2337/dc12-1365. Epub 2012 Dec 17

41. Melander A. Kinetics-effect relations of insulin-releasing drugs in patients with type 2 diabetes: brief overview. Diabetes. 2004;53 Suppl 3:S151-5.

42. Inoue T, Shibahara N, Miyagawa K, Itahana R, Izumi M, Nakanishi T, et al. Pharmacokinetics of nateglinide and its metabolites in subjects with type 2 diabetes mellitus and renal failure. Clin Nephrol. 2003;60:90-5.

43. Hasslacher C. Safety and efficacy of repaglinide in type 2 diabetic patients with and without impaired renal function. Diabetes Care. 2003;26:886-91.

44. Ryder RE. Pioglitazone has a dubious bladder cancer risk but an undoubted cardiovascular benefit. Diabetic Med. 2015;32(3):305-13. doi: 10.1111/dme.12627. Epub 2014 Dec 3.

45. Levin D, Bell S, Sund R, Hartikainen SA, Tuomilehto J, Pukkala E, et al. Pioglitazone and bladder cancer risk: a multipopulation pooled, cumulative exposure analysis. Diabetologia. 2015;58(3):493-504. doi: 10.1007/s00125-014-3456-9. Epub 2014 Dec 7.

46. Snyder RW, Berns JS. Use of insulin and oral hypoglycemic medications in patients with diabetes mellitus and advanced kidney disease. Semin Dial. 2004;17:365-70.

47. Bergman AJ, Cote J, Yi B, Marbury T, Swan SK, Smith W, et al. Effect of renal insufficiency on the pharmacokinetics of sitagliptin, a dipeptidyl peptidase-4 inhibitor. Diabetes Care. 2007:30:1862-4.

48. Graefe-Mody U, Friedrich C, Port A, Ring A, Retlich S, Heise T, et al. Effect of renal impairment on the pharmacokinetics of the dipeptidyl peptidase-4 inhibitor linagliptin(*). Diabetes Obes Metab. 2011;13:939-46.

49. Kalra S. Sodium Glucose Co-Transporter-2 (SGLT2) Inhibitors: A Review of Their Basic and Clinical Pharmacology. Diabetes Ther. 2014;5:355-66.

50. Linnebjerg H, Kothare PA, Park S, Mace K, Reddy S, Mitchell M, et al. Effect of renal impairment on the pharmacokinetics of exenatide. $\mathrm{Br} J \mathrm{Clin}$ Pharmacol. 2007:64:317-27.

51. Johansen $\mathrm{OE}$, Whitfield $\mathrm{R}$. Exenatide may aggravate moderate diabetic renal impairment: a case report. Br J Clin Pharmacol. 2008;66(4):568-9. doi: 10.1111/j.1365-2125.2008.03221.x. Epub 2008 May 15.

52. US Food and Drug Administration. Information for Healthcare Professionals: Reports of Altered Kidney Function in patients using Exenatide (Marketed as Byetta). 2009.

53. Davidson JA, Brett J, Falahati A, Scott D. Mild renal impairment and the efficacy and safety of liraglutide. Endocr Pract. 2011;17:345-55.

54. Albiglutide Full Prescribing Information. 2014. https://www.gsksource.com/ pharma/content/dam/GlaxoSmithKline/US/en/Prescribing_Information/ Tanzeum/pdf/TANZEUM-PI-MG-IFU-COMBINED.PDF.

55. Dulaglutide Full Prescribing Information. 2015. http//pililly.com/us/trulicity-uspi.pdf.

56. Chang YT, Wu JL, Hsu CC, Wang JD, Sung JM. Diabetes and end-stage renal disease synergistically contribute to increased incidence of cardiovascular events: a nationwide follow-up study during 1998-2009. Diabetes Care. 2014;37:277-85.

57. ADA. Cardiovascular disease and risk management. Sec. 8. In standards of medical care in diabetes - 2015. Diabetes Care. 2015;38:S49-57.

\section{Submit your next manuscript to BioMed Central and take full advantage of:}

- Convenient online submission

- Thorough peer review

- No space constraints or color figure charges

- Immediate publication on acceptance

- Inclusion in PubMed, CAS, Scopus and Google Scholar

- Research which is freely available for redistribution 